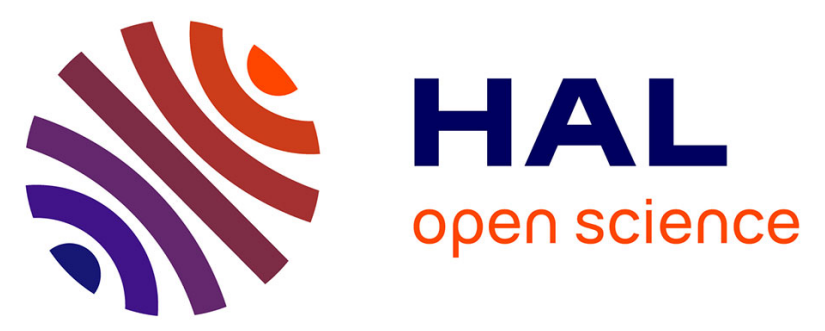

\title{
On the role of activation mode in the plasma- and hot filaments-enhanced catalytic chemical vapour deposition of vertically aligned carbon nanotubes \\ Costel Sorin Cojocaru, Francois Le Normand
}

\section{- To cite this version: \\ Costel Sorin Cojocaru, Francois Le Normand. On the role of activation mode in the plasma- and hot filaments-enhanced catalytic chemical vapour deposition of vertically aligned carbon nanotubes. Thin Solid Films, 2006, 515, pp.53-58. 10.1016/J.TSF.2005.12.137 . hal-00541134}

\author{
HAL Id: hal-00541134 \\ https://hal.science/hal-00541134
}

Submitted on 2 Mar 2013

HAL is a multi-disciplinary open access archive for the deposit and dissemination of scientific research documents, whether they are published or not. The documents may come from teaching and research institutions in France or abroad, or from public or private research centers.
L'archive ouverte pluridisciplinaire $\mathbf{H A L}$, est destinée au dépôt et à la diffusion de documents scientifiques de niveau recherche, publiés ou non, émanant des établissements d'enseignement et de recherche français ou étrangers, des laboratoires publics ou privés. 


\title{
Thin Solid Films
}

515 (2006) $53-58$

DOI: http://dx.doi.org/10.1016/j.tsf.2005.12.137

\section{On the role of activation mode in the plasma- and hot filaments- enhanced catalytic chemical vapour deposition of vertically aligned carbon nanotubes}

\author{
C.S. Cojocaru ${ }^{1}$, F. Le Normand \\ Groupe Surfaces and Interfaces, IPCMS, UMR 7504 CNRS, Bât 69, 23, rue du Loess, 67034 Strasbourg Cedex, France \\ ${ }^{1}$ Present address: Laboratoire de Physique des Interfaces et des Couches Minces (UMR 7647), Ecole Polytechnique, 91128 Palaiseau Cedex, France.
}

\begin{abstract}
Catalytic chemical vapor deposition (CCVD) with different activation modes (thermal; hot filaments-enhanced; direct current plasma-enhanced and both hot filament and direct current plasma-enhanced) are achieved in order to grow vertically aligned carbon nanotubes (VA CNTs). By widely varying the power of the different activation sources of the gas (plasma, hot filaments, substrate heating) while keeping identical the substrate temperature $(973 \mathrm{~K})$ and the catalyst preparation, the results point out the important role of ions in the nucleation of carbon nanotubes (CNTs), as well as the etching behaviour of highly activated radicals such as $\mathrm{H}^{*}$ in the selective growth of vertically aligned films of CNTs. Moreover, it is demonstrated that, within the deposition conditions (temperature, pressure, flow rate) used in this study, oriented carbon nanotubes can be grown only when both ions, mainly generated by the gas discharge plasma, and highly reactive radicals, mainly formed by the hot filaments, are produced in the gas phase. We propose that highly energetic ions are needed to nucleate the carbon nanotubes by increasing the carbon concentration gradient whereas the highly reactive radicals allow the selective growth of vertically aligned CNTs by preventing carbon deposition on the whole surface through chemical etching of edge carbons in graphene sheets.
\end{abstract}

Keywords: Carbon nanotubes; Carbon nanoparticles; Catalytically grown carbon; Chemical vapour deposition; Transmission electron microscopy

\section{Introduction}

Carbon nanotubes (CNTs) are currently produced by many pathways. Among them generally low temperature preparation techniques by chemical vapor deposition (CVD) are considered as the most convenient ones for applications in electron field emission and for any applications required to grow vertically aligned nanotubes on a flat film [1]. In these methods, nanoparticles of a transition metal like Fe, Co, Ni, Mo, etc., catalyze the CNT growth. The gas mixture is either thermally decomposed on the substrate surface, or is activated by processes such as hot filaments (HF), direct current discharge (DC), microwave (MW) plasma, or by any combination of these processes of gaseous decomposition. For a review of the thermal and plasma-activated CVD processes, the reader can report to Refs. [1,2] and [3-5], respectively. On a fundamental point of view, the mechanism of CNT nucleation and growth has not yet been firmly assessed: either growth starting from the top (tip growth mechanism) or starting from the base (root growth mechanism) of the growing CNT has been yet proposed [2]. However, the deposition conditions, as well as the preparation of the catalysts, are too widely varying in the literature for useful and rational comparisons. In this paper, several catalytic CVD (CCVD) depositions of carbon nanos- tructures with different modes of gas activation have been carried out to grow CNTs, while keeping constant the substrate temperature to $973 \mathrm{~K}$, the initial gas composition, flow rate, pressure and catalyst preparation. The gas activation is achieved by thermal heating of the substrate (T CCVD); or by heating by hot filaments (HF CCVD); or by a direct current discharge plasma (DC CCVD) or finally both by hot filaments and by direct current discharge plasma (DC HF CCVD). Identical preparation of Co catalytic nanoparticles is carried out by ultra high vacuum evaporation at high temperature. By qualitatively comparing these different gas activation modes (nature and concentration of neutral, activated and ionized species, energy distribution, etc.), it is expected to provide new insight into the understanding of the complex CNTs nucleation and growth. The catalyst and the deposited carbon were 
characterized by high-resolution transmission electron microscopy (HRTEM), scanning electron microscopy (SEM) and Raman spectroscopy.

\section{Experimental}

\subsection{Catalyst preparation}

A $\mathrm{SiO}_{2}$ layer of $8 \mathrm{~nm}$ thickness was deposited by an ECR plasma process on a $\mathrm{Si}(100)$ sample (Sb n-doped with $\mathrm{q}=3 \mathrm{mV} \mathrm{cm})$. The $\mathrm{SiO}_{2} / \mathrm{Si}(100)$ sample was then transferred into a stainless steel ultra high vacuum (UHV) preparation chamber (base vacuum 10 $0^{-10}$ mbar). Co metal (grade 99.995) was evaporated with an OMICRON EFM3 effusive source at a pressure within $0.7-2 \times 10^{-9}$ mbar on the sample heated at $925 \mathrm{KT} 20 \mathrm{~K}$ during $30 \mathrm{~min}$. Co nanoparticles with a narrow size distribution within 10-15 nm were obtained. Co is in a metallic state, as checked by in situ X-ray photoemission spectroscopy (XPS).

\subsection{Growth of carbon nanostructures}

The sample was further in situ transferred to an UHV CVD chamber for the growth of the carbon nanostructures, which has been described elsewhere in more details [6]. The UHV base pressure is lower than $10^{-9}$ mbar. The sample is heated with $\mathrm{H}_{2}$ to $973 \mathrm{~K}$ at a constant rate of $10 \mathrm{~K} / \mathrm{min}$. The variable experimental parameters are summarized in Table 1. The gas mixture $\left(\mathrm{C}_{2} \mathrm{H}_{2}+\mathrm{H}_{2}\right)$ was thermally activated by heating of the substrate with an infrared lamp on the rear of the sample, or by heating with four tungsten hot filaments at $8 \mathrm{~mm}$ above the sample (diameter 15/100 mm; filament power $\mathrm{P}_{\mathrm{F}}=150 \mathrm{~W}$ corresponding to a filament temperature $\mathrm{T}_{\mathrm{F}} 2173 \mathrm{~K}$ ). The gas mixture can also be kinetic energyactivated by a direct current discharge plasma ignited between two independent electrodes at $\mathrm{V}_{\mathrm{p}}=310 \mathrm{~T} 10 \mathrm{~V}$. A small negative extraction voltage $V_{e}$ (between -5 and $-20 \mathrm{~V}$ ) was set between the cathode and the sample. This allowed to withdraw in a controlled way an extraction current $\mathrm{I}_{\mathrm{e}}$ from the

Table 1

Parameters of the CNTs growth for the different CVD processes

\begin{tabular}{|c|c|c|c|c|}
\hline Process & T CCVD & HF CCVD & DC CCVD & DC HF CCVD \\
\hline $\mathrm{P}_{\mathrm{F}}(\mathrm{W})$ & - & 150 & - & 150 \\
\hline $\mathrm{T}_{\mathrm{F}}(\mathrm{K})$ & - & 2173 & - & 2173 \\
\hline $\mathrm{d}_{\mathrm{CS}}(\mathrm{mm})^{\mathrm{a}}$ & - & 5 & 5 & 5 \\
\hline$V_{p}(V)^{b}$ & - & - & 320 & $300 \mathrm{~T} 10$ \\
\hline$I_{p}(m A)^{b}$ & - & - & 10 & 2.75 \\
\hline$V_{e}(V)$ & - & - & 10 & 5 \\
\hline $\mathrm{I}_{\mathrm{e}}(\mathrm{mA})$ & - & - & 3 & 1.5 \\
\hline $\mathrm{P}_{\mathrm{e}}=\mathrm{I}_{\mathrm{e}} \times \mathrm{V}_{\mathrm{e}}(\mathrm{mW})$ & - & - & 30 & 7.5 \\
\hline $\mathrm{P}_{\mathrm{e}} / \mathrm{P}_{\mathrm{F}}\left(10^{-3}\right)$ & - & 0 & $\mathrm{~V}$ & 0.05 \\
\hline
\end{tabular}

Other conditions are: substrate temperature $=973 \mathrm{~K}$; $\left[\mathrm{C}_{2} \mathrm{H}_{2}\right]=20 \%$; flow rate $\mathrm{D}=100 \mathrm{sccm}$; $\mathrm{P}=15$ mbar; time of growth, $\mathrm{t}=15 \mathrm{~min}$.

${ }^{a} \mathrm{~d}_{\mathrm{CS}}$ is the distance between the bottom couple of filaments and the substrate.

${ }^{b} I_{p}$ and $V_{p}$ are not operating parameters. They depend on the quality of the coating of the electrodes, the cleanliness of the walls, the electrodes, the substrate and filaments holders, and they may shortly vary in the course of the process. polarisation plasma that was focussed onto the substrate. The activation power $\left(\mathrm{P}_{\mathrm{e}}=\mathrm{I}_{\mathrm{e}} \times \mathrm{V}_{\mathrm{e}}\right)$ on the sample, less than $1 \mathrm{~W}$, was too small to contribute to the sample heating. As displayed in Table 1, the temperature of the sample, and the CVD gas conditions (pressure, gas composition, flow rate) were set constant for all experiments, while the modes of gas activation were allowed to continuously vary.

\subsection{CNTs characterization}

The samples were examined by HRTEM on a TOPCON 002B microscope operating at $200 \mathrm{kV}$. SEM observations were performed on a XL30S-FEG PHILIPS generally working at $3 \mathrm{KV}$. Raman spectra were recorded on a Renishaw spectrometer using a He-Ne laser at $\mathrm{k}=632.8 \mathrm{~nm}(\mathrm{hm}=1.96 \mathrm{eV})$ equipped with a Notch filter and working in the backscattering geometry.

\section{Results}

\subsection{Thermal CCVD}

The thermal CCVD is the first growth mode studied. The gaseous mixture is decomposed only over the heated surface of the sample. The SEM image shows however that the surface is rather uniform (Fig. 1A) with a very weak carbon deposition, as checked by XPS. The TEM images of the sample reveal that the Co particles are encapsulated by turbostratic graphitic carbon (Fig. 2A). Lower magnitude images show that carbon strips connect these metallic particles, whereas the support is mostly let free of carbon. Very weak carbon contributions are recorded in the noisy Raman spectrum and D and G bands of carbon are hardly evidenced (Fig. 3A).

\subsection{HF CCVD}

In the HF CCVD mode, the gas mixture is activated both by the hot filaments and by the thermal heating of the sample. As the hot filaments are heated to around $2173 \mathrm{~K}$, it is expected that most of the hydrocarbon and part of the hydrogen is decomposed into radicals at this temperature. The intensity collected onto the sample with the plasma switched off is around $10 \mathrm{AA}$, and it can be inferred that the concentration of ions is very weak. Stripes of curved and closed graphitic shells encapsulating the metallic particles are well evidenced by HRTEM. Both SEM (Fig. 1B) and TEM (Fig. 2B) at low magnification confirm that most of the carbon accumulates around the metallic particles, which are clearly visible. The Raman spectrum displays an important and narrow D contribution at $1327 \mathrm{~cm}^{-1}$, but a small and broad G contribution around $1595 \mathrm{~cm}^{-1}$ and another even smaller one around $1500 \mathrm{~cm}^{-1}$ (Fig. 3B). In conclusion, the activation of the gas phase by hot filaments promotes a catalytic activity of the metallic nanoparticles for carbon decomposition leading to their encapsulation or to large stripes of high quality graphene planes. However the Raman spectrum suggests that the nature of carbon deposited is more complex than either graphite 
A

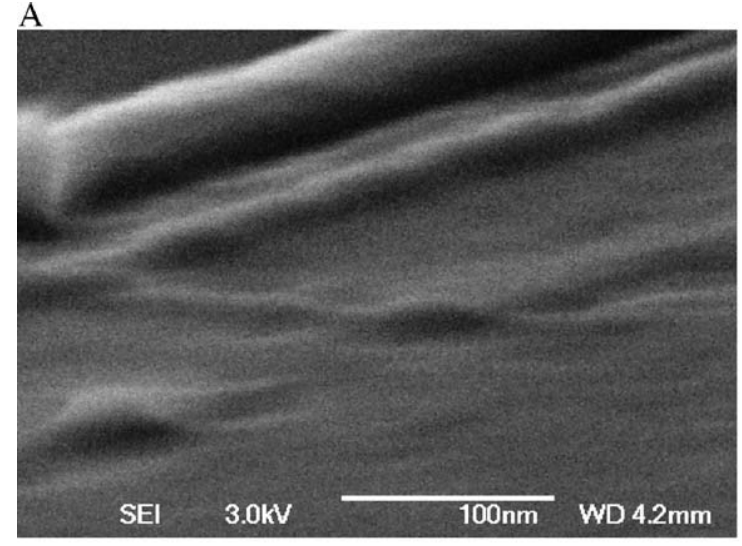

C

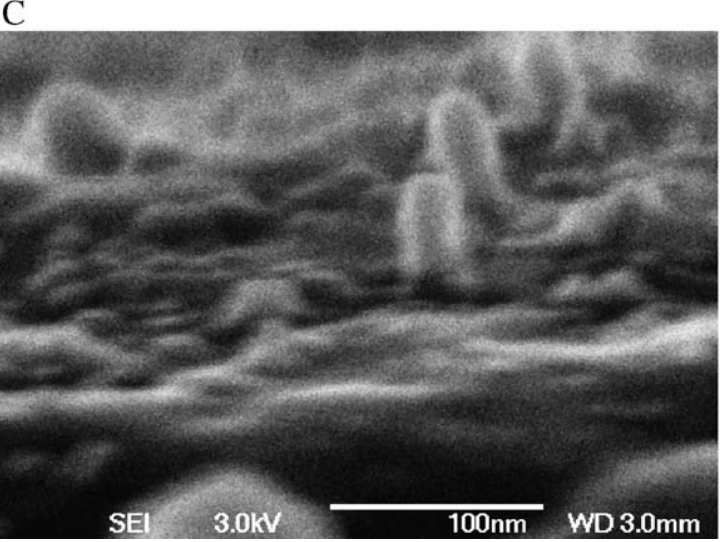

$\mathrm{B}$

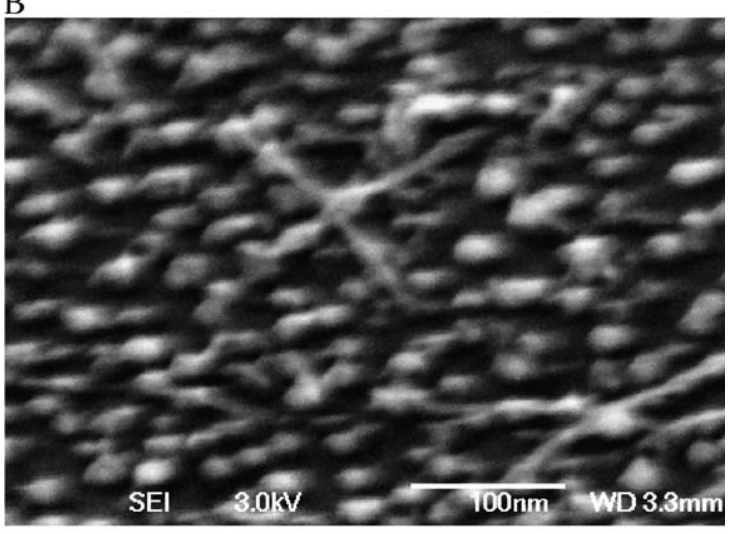

$\mathrm{D}$

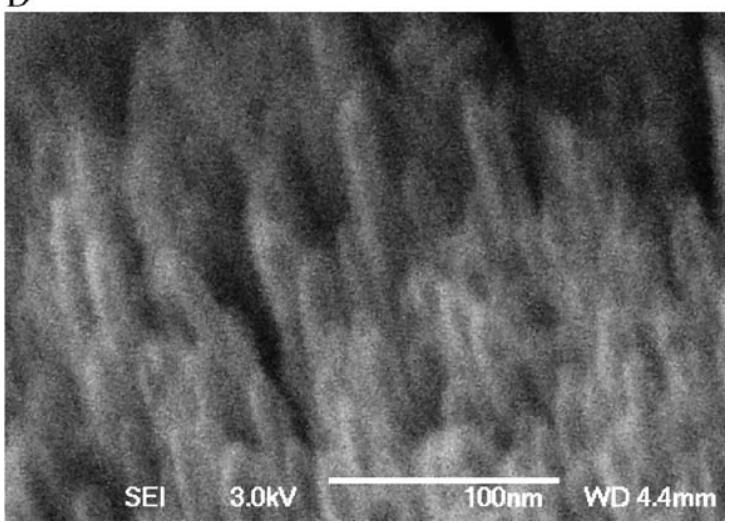

Fig. 1. Sequence of SEM images on: (A) the T CCVD (the straight line above is due to the scratching of the deposit for TEM examinations); (B) the HF CCVD; (C) the DC CCVD; and (D) the DC HF CCVD sample.

compound or graphene sheets. Anyway carbon nanotubes cannot be observed while using such activation mode.

\subsection{CCVD}

In the DC CCVD mode, the gas mixture is mainly activated by high direct current discharge plasma maintained between a set of electrodes above the sample, giving rise to plasma with formation of ions through impact collisions between electrons and molecules, and formation of radicals and activated molecules through collisions between molecules, ions and electrons. Some of these ions are extracted through the small negative polarisation $V_{e}$ set between the cathode and the sample and impinge the surface of the sample. It is clear by SEM examination that a thick and uniform carbon layer is now deposited (Fig. 1C), of thickness estimated larger than $10 \mathrm{~nm}$ from additional XPS measurements. Sometimes we do also observe some sharp and short vertically aligned whiskers that could be identified to carbon nanotubes or carbon nanofibers merging from the surface, but they are scarcely spread on the surface as evidenced by SEM observations (Fig. 1C). The nature of the carbon is mostly amorphous (Fig. 2C). This is confirmed by the Raman spectrum with two large and broad $\mathrm{D}$ and $\mathrm{G}$ lines at $1329 \mathrm{~cm}^{-1}$ and $1599 \mathrm{~cm}^{-1}$, indicative of many defects of $\mathrm{sp}^{3}$-type in the intense amorphous carbon layer (Fig. 3C). In conclusion, the DC CCVD process mainly leads to a widespread and amorphous deposition of carbon.

\subsection{HF CCVD}

In the DC HF CCVD mode, both the formation of plasma and the decomposition of the gas on the heated filaments lead to a high rate of reactive ions, radicals and activated molecules in the gas mixture above the sample. Within these conditions, strong modifications occur in the nature of the deposited carbon. The SEM (Fig. 1D) as well as the TEM images (Fig. 2D) now show clearly a film of aligned and long carbon nanotubes or carbon nanofibers vertically oriented relative to the surface. Moreover the tubes are of the bamboo-type with always a metallic particle on top of the tubes. These metallic particles exhibit now an anisotropic shape rather than the isotropic shape observed in the previous CCVD processes. In addition, the high resolution shows some defects within the graphitic shells. The lateral size is around $15-20 \mathrm{~nm}$ with a narrow size distribution. This size distribution is quite similar to the initial Co catalytic nanoparticles. The Raman spectrum (Fig. 3D) exhibits very sharp D and G bands with many narrow substructures within these band domains. The sharp and narrow $\left(F W H M=13 \mathrm{~cm}^{-1}\right) \mathrm{G}$ band at $1591 \mathrm{~cm}^{-1}$ has two weak substructures on each side at $1555 \mathrm{~cm}^{-1}$ and $1606 \mathrm{~cm}^{-1}$, respectively, quite characteristic of the occurrence of CNTs [1]. The small FWHM of band G and the weak D band are both qualitative indications of the absence of any other carbon deposit as well as the absence of many defects within the nanotubes. In conclusion, vertically aligned carbon nanotubes 

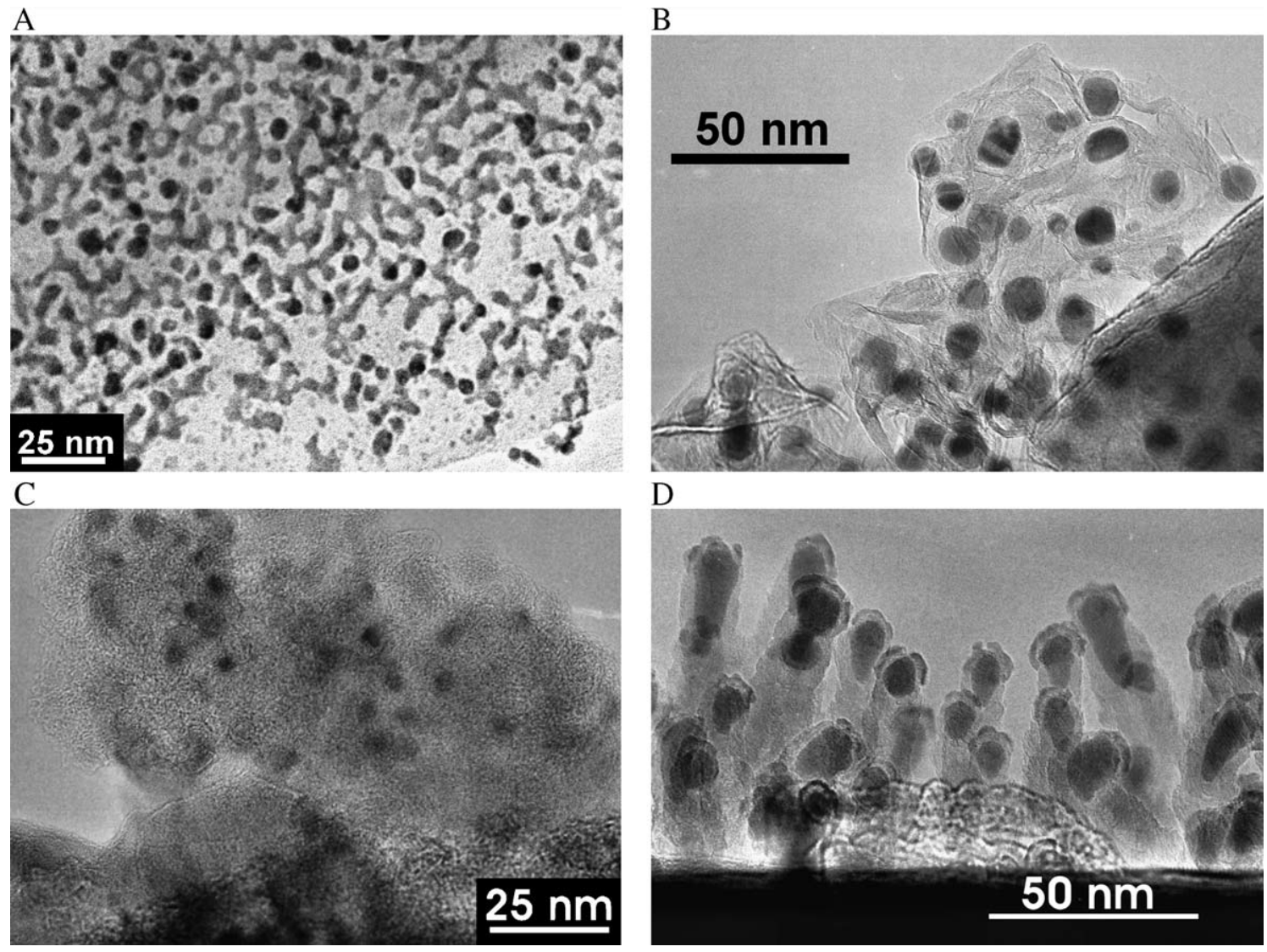

Fig. 2. Sequence of HRTEM images (high magnitude) on: (A) T CCVD (the arrows indicate tubular graphitic planes escaping from the metallic particles); (B) HF CCVD; (C) DC CCVD; and (D) DC HF CCVD samples, respectively.

are observed only when combining, within the experimental conditions used in this study (sample preparation, CVD conditions, ..etc.), gas phase activation mode with hot filaments and plasma discharge (DC HF CCVD process).

\section{Discussion}

As ascertained by SEM, TEM and Raman spectroscopy, the nature of the deposited carbon in the CCVD process is strongly dependent of the activation mode of the gas phase. The literature provides a great deal of reports of CNTs growth using either TCCVD [7,8], or HF CCVD [9-11], or DC CCVD [1217], or DC HF CCVD [18-21] activation processes. However, it must be recalled that the experimental conditions are so different from one report to another one, as far as the CVD deposition conditions (substrate temperature, pressure, nature and concentration of the gas mixture) and the catalyst preparation (nature of the catalyst and substrate, density and size of the catalytic nanoparticles, etc.) are concerned, that it is difficult to extract some rationale for the optimization of the nucleation and growth of carbon nanotubes. The occurrence and the optimization of vertically aligned CNTs might concern both the preparation of catalysts with the desired size, as the size of the CNT is in direct relationship with the size of the catalyst, and the subsequent CVD conditions of nucleation and growth. Thus, successful growth of CNTs or CNFs was reported at $973 \mathrm{~K}$ by thermal CCVD or HF CCVD in other reports, but with different preparation of the catalysts and CVD overall growth conditions. The reasons why CNTs cannot be grown here by TCCVD or HF CCVD can be explained by the very low pressure (15 mbar instead of $1000 \mathrm{mbar}$ ) and the low carbon concentration (diluted by $20 \%$ instead of around $100 \%$ ) in the gas mixture. In addition, the CNTs or CNFs deposited are generally not vertically aligned, especially when the gas mixture is thermally or hot filaments activated. The alignment has been explained by the electric field created between the anode and the sample working as a cathode in a plasmaactivated process [22]. No electric field is present in the $\mathrm{T}$ CCVD or the HF CCVD processes. Forests of aligned singlewall CNTs were recently grown however by thermal CCVD $[7,8]$. In these cases the alignment can be obtained through mutual van der Waals interactions between the growing CNTs and with a high density of the small sized catalytic nanoparticles. Finally, there are recent reports that directly compare DC CCVD and DC HF CCVD processes with the development of a gas phase model $[16,17]$. The conclusions were that the hot filaments play a minor role. However ammonia was used in the gas phase instead of hydrogen in the present work. In a partial conclusion, it must be reminded that the different gas phase activation pathways here used might not correspond to an optimized process to growth carbon nanotubes in each of the CCVD mode used here. The main interest of this study is to provide a "photography" of different activation modes for the growth of vertically aligned carbon nanotubes under strictly 


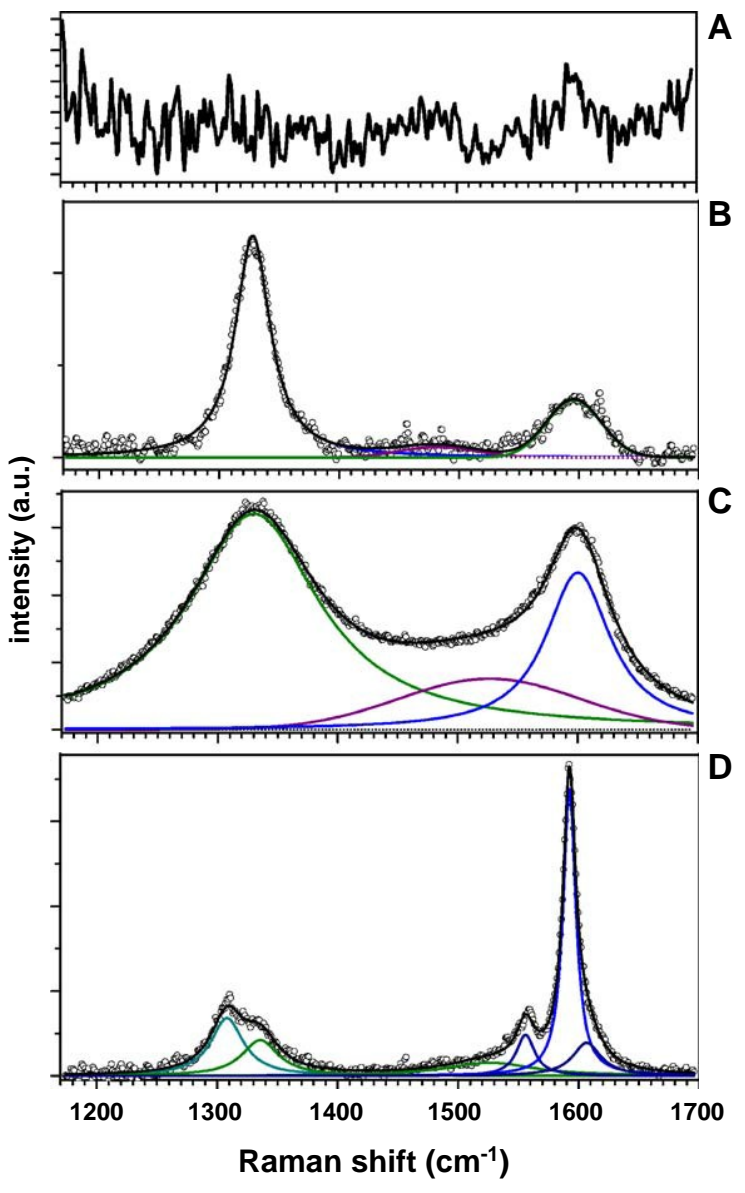

Fig. 3. Sequence of Raman spectra on: (A) the T CCVD; (B) the HF CCVD; (C) the DC CCVD; and (D) the DC HF CCVD sample. The contributions are fitted with Gaussian-lorentzian line shapes.

identical catalyst preparation and overall CVD conditions, with some qualitative elements of comparison between different gas phase activations.

At $\mathrm{T}=973 \mathrm{~K}, \mathrm{P}=15$ mbar, $20 \% \mathrm{C}_{2} \mathrm{H}_{2}$ mixed with $\mathrm{H}_{2}$ decomposed on 10- to 15-nm-sized Co particles, it is thus found that the growth of nanotubes needs the presence of both ions with high kinetic energy, generated by the DC plasma, and highly activated radicals, mostly generated by the hot filaments. We believe ions play a crucial role in the nucleation of the nanotubes by comparing the carbon deposition in the HF CCVD and the DC HF CCVD modes, respectively. In the former case, carbon encapsulates the nanoparticle and poisons it on its whole surface for further growth. Reversely, in the late case, the particles take now an oblong shape and the top surface of the particle remains available for hydrocarbon dissociation and for subsequent CNT growth according to the model first proposed by Baker [23]. This difference can be explained by the high kinetic energy of the ions impinging the surface of the nanoparticle (non-thermalized surface) that induces a gradient of carbon concentration between the top surface and the bottom surface at the interface between the substrate $\mathrm{SiO}_{2} / \mathrm{Si}(100)$ and the Co nanoparticle. This explains also why the nanoparticle takes an oblong shape through both carbon and Co inter-diffusion. Ions, that closely follow the electric field as nanotubes are growing in the extraction plasma sheath, maintain an orientation of the CNT in the direction normal to the surface. It is proposed that these ions sputter carbon atoms that can merge outside of the surface of the catalytic Co nanoparticles. Thus, it is generally observed that the nanotubes contain the amount of graphitic shells just required by the shadowing of the top nanoparticle [24]. But now, why are there no or very few CNTs observed when the DC CCVD mode is used whereas ions are also formed in the gas phase? This behaviour indicates that the presence of highly reactive radical species, like atomic hydrogen produced by hot filaments, is also required for the growth of CNTs. The difference between the DC CCVD and DC HF CCVD modes can be relied to the deposition of a large amount of amorphous carbon in the former case that spreads out on the surface of the substrate, whereas growth of CNTs only localized to the Co nanoparticle area occurs in the DC HF CCVD case. This could be relied to an important chemical etching of highly reactive radicals such as $\mathrm{H}^{*}$ that preferentially react on edge carbon of graphene sheets. The edge carbons in a graphene sheet (prismatic carbon) are fivefold more reactive to $\mathrm{H}^{\cdot}$ radicals than carbon inside a graphene sheet [25]. Therefore, the spreading of carbon, which first develops at the interface of the metallic nanoparticle and the substrate, is now forbidden over the whole surface of the substrate.

From these results, as well as from the results of other experiments where either the plasma power or the power of the hot filaments are continuously varied [26], it is possible to plot a schematic 3D carbon phase diagram with the three modes of gas phase activation as parameters (Fig. 4). This phase diagram points out that, at a very low power of hot filaments, with hydrogen in the gas mixture, amorphous carbon will be formed rather than CNTs. At very low temperatures or very low plasma power, Co particles are encapsulated and thus poisoned for carbon growth. At high plasma power, filled carbon nanofibers, without central hollow channel, are produced only. Growth of vertically aligned CNTs or CNFs thus proceeds in a narrow window of activation parameters. Such qualitative carbon phase diagram has been recently reported, but with a $\mathrm{C}_{2} \mathrm{H}_{2} /$ $\mathrm{NH}_{3}$ gas mixture [5].

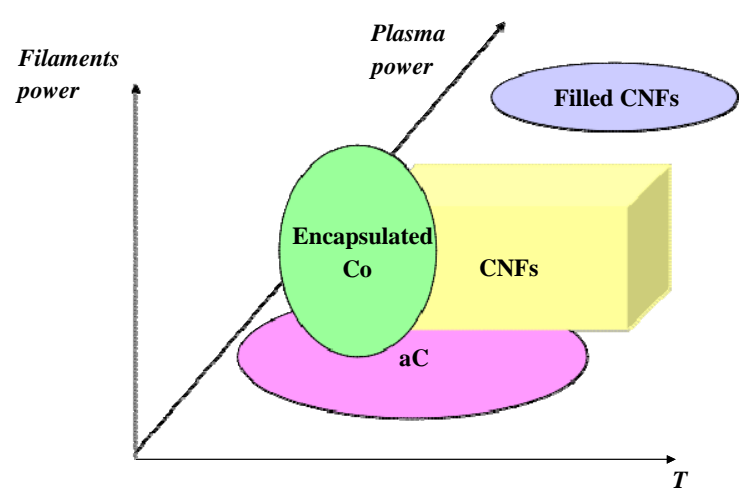

Fig. 4. A schematic phase diagram of the carbon species grown according to the activation modes of the gas phase containing hydrogen: thermal heating from the substrate; thermal heating by hot filaments above the sample and direct current discharge plasma. 


\section{Conclusion}

As main results of this study, we demonstrate that, with identical CVD deposition conditions and preparation of the Co catalysts, oriented carbon nanotubes can be grown only when using both ions, mainly produced both by a gas discharge plasma, and highly reactive radicals, mainly produced by hot filaments (DC HF CCVD process). A synergy in the effect of these two gas species is observed in the nucleation and growth of CNTs. We propose that highly energetic ions are needed for the nucleation of the CNTs by increasing the carbon concentration gradient. Reversely, highly reactive radicals as $\mathrm{H}^{*}$ prevent the spreading of carbon over the whole surface of the substrate by preferential chemical etching, and thus allow the selective growth of CNTs.

\section{Acknowledgements}

C.S.C. acknowledges the "Région Alsace" for a grant. J. Faerber and G. Ehret are kindly acknowledged for SEM and TEM observations, respectively.

\section{References}

[1] M.S. Dresselhaus, G. Dresselhaus, P. Avouris, Carbon Nanotubes: Synthesis, Structure, Properties and Applications, Springer, Berlin, 2001, p. 29.

[2] T.W. Ebbesen, in: T.W. Ebbesen (Ed.), Carbon Nanotubes: Preparation and Properties, CRC Press, Boca Raton, 1997.

[3] A. Huczko, Appl. Phys., A 74 (2002) 617.

[4] M. Meyyappan, L. Delzeit, A. Cassell, D. Hash, Plasma Source Technol. 12 (2002) 205

[5] A.V. Melechko, V.I. Merkulov, T.E. MacKnight, M.A. Guillorn, K.L. Klein, D.H. Lowndes, M.L. Simpson, J. Appl. Phys. 97 (2005) 041301.
[6] C.S. Cojocaru, M. Larijani, D.S. Misra, M.K. Singh, P. Veis, F. Le Normand, Diamond Relat. Mater. 13 (2004) 270.

[7] Y. Murakami, S. Yamakita, T. Okubo, S. Maruyama, Chem. Phys. Lett. 375 (2003) 393.

[8] K. Hata, D.N. Futaba, K. Mizuno, T. Namai, M. Yumura, S. Iijima, Science 306 (2004) 1362.

[9] Y.F. Zhang, Y.H. Tang, Y. Zhang, C.S. Lee, I. Bello, S.T. Lee, Chem. Phys. Lett. 330 (2000) 48.

[10] R. Kurt, C. Klinke, J.M. Bonard, K. Kern, A. Karami, Carbon 39 (2001) 2163.

[11] A.C. Dillon, A.H. Mahan, J.L. Alleman, M.J. Heben, P.A. Parilla, K.M. Jones, Thin Solid Films 430 (2003) 292.

[12] M. Chhowalla, K.B.K. Teo, C. Ducati, N.L. Rupesinghe, G.A.J. Amaratunga, A.C. Ferrari, D. Roy, J. Robertson, W.I. Milne, J. Appl. Phys. 90 (2001) 5308.

[13] V.I. Merkulov, A.V. Melechko, M.A. Guillorn, D.H. Lowndes, M.L. Simpson, Chem. Phys. Lett. 350 (2001) 381.

[14] R.E. Morjan, V. Maltsev, O.A. Nerushev, Y. Yao, L.K.L. Falk, E.E.B. Campbell, Chem. Phys. Lett. 383 (2004) 385.

[15] C. Ducati, I. Alexandrou, M. Chhowalla, J. Robertson, G.A.J. Amaratunga, J. Appl. Phys. 95 (2004) 6387.

[16] D. Hash, D. Bose, D.R. Govindan, M. Meyyappan, J. Appl. Phys. 93 (2003) 6284.

[17] K.B.K. Teo, M. Meyyappan, R.G. Lacerda, N.L. Rupesinghe, M.S. Bell, S.H. Dalal, D. Bose, T.R. Govindan, B.A. Cruden, D. Hash, M. Chhowalla, G.A.H. Amaratunga, W.I. Milne, Nano Lett. 4 (2004) 921.

[18] Z.P. Huang, J.W. Xu, Z.F. Ren, J.H. Wang, M.P. Siegal, P.N. Provencio, Appl. Phys. Lett. 73 (1998) 3845.

[19] Y. Chen, L. Guo, S. Patel, D.T. Shaw, J. Mater. Sci. 35 (2000) 5517.

[20] J.H. Han, W.S. Yang, J.B. Yoo, C.Y. Park, J. Appl. Phys. 88 (2000) 7363.

[21] Ch. Taschner, F. Pacal, A. Leonhardt, P. Spatenka, K. Bartsch, A. Graff, R. Kaltofen, Surf. Coat. Technol. 174 (2003) 81.

[22] Y. Zhang, A. Chang, J. Cao, Q. Wang, W. Kim, Y. Li, N. Morris, E. Yenilmez, J. Kong, H. Dai, Appl. Phys. Lett. 79 (2001) 3155.

[23] R.T.K. Baker, Carbon 27 (1989) 315.

[24] C.S. Cojocaru, F. Le Normand, J. Nanosci. Nanotechnol. (2006).

[25] W.L. Hsu, J. Vac. Sci. Technol., A 6 (1988) 1803.

[26] F. Le Normand, C.S. Cojocaru, A. Senger, B. Vigolo, (in press). 